\title{
Demographic profile of Cervical Cancer development: a hospital based study
}

\author{
Das CR ${ }^{1}$, Deka $\mathrm{M}^{2}$, Bose $\mathrm{S}^{3}$, Bose $\mathrm{PD}^{4}$, Das GC \\ ${ }^{1}$ Dr Chandana Ray Das MD, Assistant Professor, Department of Obstetrics \& Gynaecology, Gauhati Medical College, \\ Guwahati,Assam, ${ }^{2}$ Prof. Manab Deka, Ph.D. Department of Biological Science, Gauhati University, Assam, ${ }^{3}$ Dr Sujoy \\ Bose, Ph.D. Department of Biotechnology, Gauhati University, Assam, ${ }^{4}$ Dr Purabi Deka Bose, Ph.D. Department of \\ Biotechnology, Pandu College,Assam, ${ }^{5}$ Prof. Gokul Ch Das, MD, Professor, Department of Obstetrics \& Gynaecology, \\ Gauhati Medical College, Guwahati,Assam.
}

Address for correspondence: Dr Chandana Ray Das, E-mail: chandanaraydas@yahoo.in

\begin{abstract}
Introduction: The present study is an attempt to detect Human papilloma virus infection along with its genotype in cancer cervix and its relation with demographic profile. Methods: Cervical cancer cases were enrolled in between Jan' 2010 to Dec' 2012. One sample was collected from non cancerous area of cervix for DNA extraction and two samples were collected from cancerous area of cervix from same patient, one for DNA extraction and other one for histopathological examination to confirm our clinical diagnosis. Extracted DNA was then checked for presence of HPV DNA by PCR amplification method using MY09/11 primer. HPV genotyping was done by using specific primer for HPV16 \& HPV 18. The cases were compared with their corresponding socio demographic profile. Results: The study showed $88.88 \%$ cases found to be HPV positive in cancerous area compared to $7.4 \%$ number in non cancerous area. Out of which $95.83 \%$ cases to be HPV 16 and only $4.16 \%$ were to be HPV 18 in cervical cancer cases. There were other significant risk factor association of cervical cancer with early marriage in $70.36 \%$ and high parity $87 \%$ of cases. Conclusion: The human papilloma virus type $16 \& 18$ are the major contributing factor along with other risk factors like early marriage, illiteracy and high parity for cervical cancer in our region.
\end{abstract}

Key Words: Cervical cancer, High risk, Human Papilloma Virus, Polymerase chain reaction,

\section{Introduction}

Worldwide cervical cancer is the third most common cancer in women, and the seventh overall, with an estimated 529,000 new cases and 274,000 deaths occurring in 2008 [1]. In India 122,844 new cervical cancer cases are diagnosed and 67,477 number deaths occur annually [2]. Cervical cancer ranks as the 2 nd cause of female cancer in India. The age standardized cervical cancer incidence and mortality rates were 22 and 15 per 100,000 women [2]. In population based cancer registries (PBCR) Barshi and Chennai PBCRs have always recorded the highest incidence of cervix cancer [3]. The report of the North Eastern PBCRs indicates an Age Adjusted or Age Standardised Incidence Rates (AAR) of 25.4 per 100,000 in Aizawl district of Mizoram state followed by AARs in Imphal West district (20.5) and Kamrup Urban district (17.3)

Manuscript received: $4^{\text {st }}$ July 2014

Reviewed: $10^{\text {th }}$ July 2014

Author Corrected: $16^{\text {th }}$ July 2014

Accepted for Publication: $17^{\text {th }}$ July 2014
[3]. Human Papilloma Virus (HPV) which is mainly transmitted sexually, prevalence in cervical carcinomas has been estimated to be $99.7 \%$, higher than previously thought [4]. Particularly type 16 and type $18 \mathrm{HPV}$ are plays an important role for cervical cancer. The lag period between the oncogenic HPV infection and the invasive cervical cancer is 15-20 years. Based on the association with cervical cancer, genital HPVs are further grouped into high-risk types, and low-risk types [5]. Observations related to lower socioeconomic status and cervical cancer have already been made as poverty is the real context of India [6]. Many studies have shown that the incidence of cervical cancer, as well as survival and mortality, vary with ethnic group and socioeconomic status .In 2010, black women had the highest rate of getting cervical cancer, followed by Hispanic, white, American Indian/Alaska Native, and Asian/Pacific Islander women. [7, 8] and that incidence of cervical cancer is highest in women with the lowest socioeconomic status [8, 9]. Reasons for ethnic and socio-economic 
differences in the incidence of cervical cancer can be difficult to determine because definitions of ethnic groups and socioeconomic status are not always consistent and because ethnicity may be confounded with socioeconomic status and other variables, which may or may not be controlled for in analyses [10]. Possible reasons for social disparities in the incidence of cervical cancer include: increased likelihood of smoking, poor diet, physical inactivity and HPV infection in women with lower socioeconomic status [8]. The risk factors which has been proved to be associated with cervical cancer are poverty, poor socio-economic status, widespread ignorance, poor personal hygiene, smoking, early marriage, childbearing, high parity status, young age at the first full term pregnancy and use of oral contraceptives for five or more years, previous exposure to other sexually transmitted infections (STI), notably Chlamydia Trachomatis, some herpes simplex viruses-2 and HIV $[11,12,13]$. Studies from various part of the world that was conducted to find out the ethnic and racial composition shows that there was no predominant racial or ethnic category $[14,15]$. The age at which women engage in their first sexual intercourse has also been cited as a risk factor for cervical cancer as damage might be caused to the cervix at a time when it is still developing. The risk of getting HPV and cervical cancer in women who initiated sexual intercourse around age 15 has been shown to be quite higher risk of those who did so after age 20 [16]. Male circumcision is associated with a reduced risk of penile HPV infection and, in the case of men with a history of multiple sexual partners, a reduced risk of cervical cancer in their current female partners $[17,18]$.

\section{Aims and Objectives}

1) To detect Human papilloma virus infection in cancer cervix.

2) To identify the genotype of HPV infection.

3) To find out the demographic profile

\section{Materials and Methods}

A prospective study was carried out at the department of Biotechnology, Gauhati University in collaboration with Gynaecology Department of Gauhati Medical College and Hospital in between Jan' 2010 to Dec' 2012. All confirmed cervical cancer cases as well as suspicious cervix with VIA (Visual inspection with acetic acid) and VILLI (Visual inspection with lugol's iodine) positive cases, attended in Gynaecology OPD of Gauhati Medical College and Hospital were enrolled for the study. Patients with history of previous treatment for cervical pre-cancerous lesions or cancer were excluded. Patients' case histories including age, marital status, gravida, parity, socio-economic status, personal hygiene etc. parameters were investigated and recorded.

Study sample: From non cancerous area of cervix one sample and from cancerous area two samples were collected. For DNA extraction one sample each from non cancerous and cancerous area was taken in vials containing PBS (Phosphate buffer solution) or RNA later solution. At the same time another sample from cancerous cervical tissue was collected in formalin solution for Histo-pathological examination to confirm our clinical diagnosis.

DNA extraction was done by standard phenolchloroform method after tissue lysis using buffer and proteinase $\mathrm{K}$ digestion. The quality of DNA isolated is then checked by running in $0.8 \%$ agarose gel electrophoresis. Isolated DNA are then stored at $4^{\circ} \mathrm{C}$.

\section{HPV detection and genotyping}

Extracted DNA was then checked for presence of HPV DNA by PCR amplification method using MY09/11 primer. The primer MY09/11 is a consensus primer, targets a 450bp conserved sequence in the HPV L1 gene, and can therefore amplify a broad spectrum of HPV types. The MY09/11 primer sequences were as follows:

My09: 5'CGTCCMARRGGAWACTGATC3' My11: 5'GCMCAGGGWCATAAYAATGG3'

$\mathrm{M}=\mathrm{A}$ or $\mathrm{C}, \mathrm{W}=\mathrm{A}$ or $\mathrm{T}, \mathrm{Y}=\mathrm{C}$ or $\mathrm{T}, \mathrm{R}=\mathrm{A}$ or $\mathrm{G}$

HPV genotyping was done by using type specific primer for HPV16 and HPV18. Since, majority of the cervical cancer cases were squamous cell carcinoma which are predominantly caused by HPV16 and 18, hence our study was mainly designed for detection of HPV type 16 and 18 using type specific primer for PCR detection.

\section{Primers used for HPV16}

F: 5'TCAAAAGCCACTGTGTCCTGA3'

R: 5'GGTGTTCTTGATGATCTGCAA3'

\section{Primers used for HPV18 \\ F: 5'CCGAGCACGACAGGAACGACT3' \\ R: 5'TCGTTTTCTTCCTCTGAGTCGCTT3'}

\section{Ethical review of the proposal and the consent}

The research proposal was approved by the ethical review board of the Gauhati University. Informed consent was obtained from all participants prior to the sample collection. 


\section{Research Article}

\section{The statistical Analysis}

The association/contingency between demographic factors and HPV infection was statistically calculated by using the Chi-Square $\left(\chi^{2}\right)$ test of significance. The calculations were performed by adopting the statistical software Graph Pad InStat.

\section{Results}

In the present study, data's (cervical tissue) were collected from fifty four (54) women's age ranges from 30 yrs to 70 yrs age.

Table-1: Relation of age and detection of HPV infection and its genotype to the occurrence of carcinoma cervix

\begin{tabular}{|c|c|c|c|c|c|c|c|c|}
\hline \multirow{2}{*}{$\begin{array}{l}\text { Age of } \\
\text { patient } \\
\text { (year) }\end{array}$} & \multirow[b]{2}{*}{ cases } & \multirow{2}{*}{$\begin{array}{l}\% \text { of } \\
\text { positive } \\
\text { cases }\end{array}$} & \multicolumn{3}{|c|}{ HPV+ve (cancerous area) } & \multicolumn{3}{|c|}{ HPV+ve (noncancerous area) } \\
\hline & & & & HPV16 & HPV18 & & HPV 16 & HPV 18 \\
\hline $31-40$ & 13 & $24.07 \%$ & 13 & 11 & 2 & 4 & 4 & 0 \\
\hline $41-50$ & 27 & $50 \%$ & 27 & 27 & 0 & 0 & 0 & 0 \\
\hline $51-60$ & 10 & $18.5 \%$ & 8 & 8 & 0 & 0 & 0 & 0 \\
\hline $61-70$ & 2 & $3.7 \%$ & 0 & 0 & 0 & 0 & 0 & 0 \\
\hline $71-80$ & 2 & $3.7 \%$ & 0 & 0 & 0 & 0 & 0 & 0 \\
\hline \multicolumn{3}{|c|}{ Total patients $=54$} & $\begin{array}{l}\text { Total }=48 \\
(88.88 \%)\end{array}$ & $\begin{array}{l}46 \\
(95.83 \%)\end{array}$ & $\begin{array}{l}2 \\
(4.16 \%)\end{array}$ & $\begin{array}{l}\text { Total }=4 \\
(7.4 \%)\end{array}$ & $\begin{array}{l}4 \\
(100 \%)\end{array}$ & 0 \\
\hline
\end{tabular}

The mean age of patients was 44.99 years and the highest number of HPV positive cases belonged to patients aged 41-50 years which signifies that HPV infection happens in the early and early-middle phases of life. This indicates that the chances of carcinoma cervix are higher in premenopausal age then at postmenopausal age. Maximum number of patients $(70.37 \%)$ was from rural background.

$\mathrm{P}<0.001 \rightarrow \mathrm{HPV}$ infection is significantly associated with cervical cancer development in patient below 50 years of age.

$\mathrm{P}=0.102 \rightarrow$ though presence of HPV infection in cancerous area as well as non cancerous area was higher in the 31-40 years age group $(n=17)$ compared to $41-50$ year groups but is not significant.

$\mathrm{P}=0.422 \rightarrow$ overall HPV 16 was found to be the prominent genotype. Although the presence of HPV 16 genotype was higher in 41-50 years age group, but the difference in HPV 16 genotype distribution was not significant compared to the 31-40 years age group. Only HPV 16 was found to be present in cases where both cancerous and non cancerous areas were found to be positive for HPV infection.

Table-2: Age of marriage and age of first pregnancy

\begin{tabular}{|c|c|c|c|c|}
\hline \multirow[b]{2}{*}{ Age (in years) } & \multicolumn{2}{|c|}{ Age of marriage } & \multicolumn{2}{|c|}{ Age of pregnancy } \\
\hline & Cases & Percentage & Case & Percentage \\
\hline$<16$ & 16 & $29.6 \%$ & 13 & $24.07 \%$ \\
\hline $16-<20$ & 23 & $42.59 \%$ & 25 & $46.29 \%$ \\
\hline $20-<23$ & 10 & $18.5 \%$ & 8 & $14.8 \%$ \\
\hline$>23$ & 5 & $9.25 \%$ & 8 & $14.8 \%$ \\
\hline
\end{tabular}

$70.36 \%$ patients got pregnant before the age of 20 years and only $28.16 \%$ patients got their first child above the age of 20 years.

Table-3: Religion wise distribution of cases

\begin{tabular}{|l|l|l|}
\hline Religion & Case & Percentage \\
\hline Hindu & 50 & $92.59 \%$ \\
\hline Muslim & 4 & $7.4 \%$ \\
\hline
\end{tabular}


It was found that the occurrences of carcinoma cervix are more in Hindu population. The significantly lower incidence of carcinoma cervix in Muslim population may be due to circumcision status due to less HPV virus colonization in penis [17].

Table-4: Relation with parity

\begin{tabular}{|l|l|l|}
\hline Parity(P) & Cases & Percentage \\
\hline P1 & 2 & $3.7 \%$ \\
\hline P2 & 2 & $3.7 \%$ \\
\hline P3 & 14 & $25.92 \%$ \\
\hline P4 & 31 & $57.40 \%$ \\
\hline P5 & 5 & $9.2 \%$ \\
\hline
\end{tabular}

It has been seen that cervical cancer development is high as parity is more. $58 \%$ cases were parity 4 . The risk increases with multiple child birth. In the present study had $96.22 \%$ of females had with multiple childbirth.

Table-5: Educational Status

\begin{tabular}{|l|l|l|}
\hline Standard & Cases & Percentage \\
\hline Illiterate & 15 & $27.77 \%$ \\
\hline Up to Primary & 27 & $50 \%$ \\
\hline Up to High school level & 10 & $18.51 \%$ \\
\hline Above high school level & 2 & $3.7 \%$ \\
\hline
\end{tabular}

Table-6: HPV prevalence and HPV Genotyping

\begin{tabular}{|l|l|l|l|l|l|}
\cline { 5 - 6 } \multicolumn{2}{c}{} & \multicolumn{2}{c|}{ HPV positive } \\
\hline Area & Total & HPV-ve & HPV +ve & HPV 16 & HPV 18 \\
\hline Cancerous area & 54 & $6(11.11 \%)$ & $48(88.88 \%)$ & $46(95.83 \%)$ & $2(4.16 \%)$ \\
\hline Non cancerous area & 54 & $50(92.59 \%)$ & $4(7.4 \%)$ & 4 & 0 \\
\hline
\end{tabular}

Presence of amplifiable DNA, using primers for HPV 16 and 18 was confirmed in 48(88.88\%) out of the 54 individuals in cancerous area and in non cancerous area HPV 16 was found in 4(7.41\%) cases. High risk HPV 16 prevalence was $95.83 \%$ from the cancerous and all the $4(100 \%)$ cases from non cancerous area. HPV18 was prevalent only in $2(4.16 \%)$ cases from cancerous area. None was found from non cancerous area. The P value is $<0.0001$, considered extremely significant.

\section{Discussion}

One of the most important information from the present study was the apparent strong correlation between the ages at marriage with the chances of occurrence of carcinoma cervix. About $70.36 \%$ patients got pregnant before the age of 20 years and only $28.16 \%$ patients got their first child above the age of 20 years. The occurrence of carcinoma cervix was found to be especially prominent in patients who conceived before 20 years. In consistence with the correlation between chance of occurrence of carcinoma cervix and the age of marriage, similar relation was also observed with the age at first pregnancy by J.T. Boyd and co-workers who showed similar result with increased risk of developing carcinoma cervix in women who got pregnant before the age of 18 years [19]. In a case control study by Biswas L
$\mathrm{N}$ et al, showing maximum risk in women who reported their first intercourse at $<12$ years of age [16]. The mean age of patients was 44.99 years and the highest number of HPV positive cases belonged to patients aged 41-50 years which signifies that HPV infection happens in the early and early-middle phases of life. This indicates that the chances of carcinoma cervix are higher in premenopausal age then at postmenopausal age. In the present study had $96.22 \%$ of females had with multiple childbirth. Study by E.L. Wynder and his co-workers [20] showed that increased risk is directly proportional to parity. The role of high risk HPV infection in the formation of cervical cancer is not clearly understood. It is already documented that the majority of HPV infections are cleared spontaneously from cervical area 
by cell mediated immunity. The lower rate of clearance HPV16 infection in women less than 30 years of age was observed, on the other hand no difference in the likelihood of clearance was observed by HPV type or woman's age. Viral load is the main determinant of persistence, and persistence of HPV16 infections carries a higher risk of CIN2/3, which is inversely associated with clearance [21].

Spontaneous clearance of the HPV is one of the important contributing factors for negative result of HPV infection in non cancerous area in our study. About 7.9\% of women in the general population are estimated to harbour cervical HPV infection at a given time, and $84.1 \%$ of invasive cervical cancers are attributed to HPVs 16 or 18 [2]. HPV type 16 accounts for close to $50 \%$ of the types identified in cervical cancer and together type 16 and 18 are implicated in $70 \%$ of cervical cancers worldwide [23].

In India, HPV type 16 alone is found to be 70 to $90 \%$ prevalent while occurrence of HPV type 18 varies from 3 to $20 \%$ [22, 23, 24, 25]. High grade squamous intraepithelial lesion cytology was more frequent in women infected with HPV 16 than in those infected with HPV 18 and other types [26]. As most of the previous study conducted in India shows HPV 16 and 18 are mostly (80-90\%) prevalent in cancer cervix, in our study we have included evaluation of only HPV 16 and 18 type to reduce the financial burden. In the present hospitalbased case study, $88.88 \%$ were positive in cancerous area and only $11.12 \%$ were negative for HPV compared to $7.41 \%$ positive and 92.59 were negative among non cancerous area. Among the HPV positive cases in cancerous area $95.83 \%$ were HPV 16 and only $4.17 \%$ were HPV 18.

Comparing to the other studies in our study percentage of HPV 16 genotype was in higher side and HPV 18 was in lower side. On the other hand among $7.41 \%$ positive women in non cancerous area, all cases were HPV 16. The HPV 16 and 18 type positivity results are higher in the present study, because of inclusion criteria (all cases were clinically diagnosed or highly suspected case of carcinoma cervix). Walboomers et al. 1999 has already descried that Human Papilloma Virus (HPV) which is mainly transmitted sexually, prevalence in cervical carcinomas has been estimated to be $99.7 \%$, higher than previously thought [4]

As carcinoma cervix is the second most common malignancy among female in our region, we should work very hard to control and prevent it by more awareness among general public as well as among health care provider of the region through electronic media, newspaper and medical bulletin.

The authority should take some preventable measures by lows and publicity that may be by strict low against early marriage and multiple child birth, mandatory and free HPV vaccination to all teenage girl children, periodic health screening among all female and to provide adequate facility of conventional PAP smear at least in all community level hospital.

\section{Conclusion}

The HPV infection in cervical cancer was found $88.88 \%$ in the present study, showing a strong association of HPV infection with cervical cancer. The prevalence of HPV type16 was $96.15 \%$ and HPV18 (3.84\%), hence HPV 16 and 18 are the major etiologic factor along with other risk factors like early marriage, illiteracy and high parity for cervical cancer in our region.

Cervical cancer incidence can be brought down in women between ages of 21 to 65 years by regular screening with PAP smear every three years and those women want to lengthen the screening up to five years, screening procedure should combine with cytology (PAP smear) and human papillomavirus (HPV) testing.

Acknowledgement: The authors want to thanks all the subjects participating in the study.

\section{Funding: Nil}

Conflict of interest: None.

\section{References}

1. Ferlay J, Shin HR, Bray F, Forman D, Mathers C, Parkin DM.. Estimates of worldwide burden of cancer in 2008: GLOBOCAN 2008. Int J Cancer. 2010 Dec 15; 127(12):2893-917. doi: 10.1002/ijc.25516.

2. Ferlay J, Soerjomataram I, Ervik M, Dikshit R, Eser S, Mathers C, Rebelo M, Parkin DM, Forman D, Bray F. GLOBOCAN 2012 v1.0, Cancer Incidence and Mortality Worldwide: IARC Cancer Base No. 11. Lyon, France: International Agency for Research on Cancer; 2013. http://globocan.iarc.fr/.

3. Nandakumar A, T. Ramnath \& Meesha Chaturvedi. The magnitude of cancer cervix in India. National Cancer Registry Programme (ICMR), Bangalore, India. Indian J Med Res. 2009 Sept; 130(3); 219-21, Review. 
Research Article

4. Walboomers JM, Jacobs MV, Manos MM, Bosch FX, Kummer JA, Shah KV, Snijders PJ, Peto J, Meijer CJ, Munoz N. Human papillomavirus is a necessary cause of invasive cervical cancer worldwide. J Pathol. 1999; 8:12-19. doi: 10.1002/(SICI)1096-9896(199909)189:1<12::AIDPATH431>3.0.CO;2-F.

5. Munoz N, Bosch FX, de Sanjose S, Herrero R, Castellsague X, Shah KV, et al. Epidemiologic classification of human papillomavirus types associated with cervical cancer. N Engl J Med. 2003; 348(6):518-27.

6. Duggal R, Gangolli LV, (2005). Introduction to Review of Healthcare in India. In 'Review of Healthcare in India', Centre for Enquiry into Health and Allied Themes, pp. 3-18

7. Canters for Disease Control and Prevention (CDC). HPV associated cervical cancer rates by race and ethnicity. http:// www.cdc.gov/cancer/cervical/statistics/race.htm 2010 .

8. Clegg LX, Reichman ME, Miller BA, Hankey BF, Singh GK, Lin YD, et al. .Impact of socioeconomic status on cancer incidence and stage at diagnosis: selected findings from the surveillance, epidemiology, and end results: National Longitudinal Mortality Study. Cancer Causes Control 2009; 20(4):417-35.

9. Franceschi S, Plummer M, Clifford G, de Sanjosé S, Bosch X, Herrero R, et al. Differences in the risk of cervical cancer and human pappilomavirus infection by education level. British Journal of Cancer 2009; 101:865-70. doi: 10.1038/sj.bjc.6605224

10. Pruitt SL, Shim MJ, Mullen PD, Vernon SW, Amick BC., III Association of area socioeconomic status and breast, cervical, and colorectal cancer screening: a systematic review. Cancer Epidemiol Biomarkers Prev. 2009; 18:2579-99. doi: 10.1158/10559965.EPI-09-0135

11. Madeleine, M. M., Anttila, T., Schwartz, S. M., Saikku, P., Leinonen, M., Carter, J. J., Wurscher, M., Johnson, L. G., Galloway, D. A. and Daling, J. R. Risk of cervical cancer associated with Chlamydia trachomatis antibodies by histology, HPV type and HPV cofactors. Int. J. Cancer 2007; 120: 650-655. doi: $10.1002 /$ ijc. 22325
12. Berrington de González A, Sweetland S, Green J, et al. Comparison of risk factors for squamous cell and adenocarcinomas of the cervix: a meta-analysis. Br J Cancer 2004; 90(9):1787-91

13. Paul Satya B, Tiwary Basant K, Choudhury Arun Paul. Studies on the Epidemiology of Cervical Cancer in Southern Assam. Assam University Journal of Science \& Technology .Biological and Environmental Sciences. 2011; 7(1):36-42

14. Boyer CB, Shafer MA, Shaffer RA, Brodine SK, Pollack LM, Betsinger K, et al. Evaluation of a cognitive-behavioral, group, randomized controlled intervention trial to prevent sexually transmitted infections and unintended pregnancies in young women. Preventive Medicine 2005; 40(4):420-31. DOI: 10.1016/j.ypmed.2004.07.004

15. Bull SS, Posner SF, Ortiz C, Beaty B, Benton K, Lin $\mathrm{L}$, et al. Power for reproductive health: Results from a social marketing campaign promoting female and male condoms. Journal of Adolescent Health 2008; 43:71-8. doi: 10.1016/j.jadohealth.2007.12.009.

16. Biswas LN, Manna B, Maiti PK, Sengupta S . Sexual risk factors for cervical cancer among rural Indian women: a case-control study. Int. J. Epidemiol 1997; 26 (3): 491-495. doi: 10.1093/ije/26.3.491

17. Castellsagué X, Bosch FX, Muñoz N .The male role in cervical cancer. Salud Publica Mex. 2003; 45 (3):345-53.

18. Castellsagué X, BoschFX, Munoz N, Meijer CJLM, Shah KV, de Sanjosé S, et al. Male circumcision, penile human papillomavirus infection, and cervical cancer in female partners. The New England Journal of Medicine 2002; 346: 1105-12. DOI: 10.1056/NEJMoa01168

19. Boyd, J.T., Doll, R. (1964). A Study of the Aetiology of Carcinoma of the Cervix Uteri. $\mathrm{Br} \mathrm{J}$ Cancer. 18(3):419-434.

20.Wynder, E.L., Cornfield, G., Schroff, P.D, Doraiswami, K.R. (1954). Study of environmental factors in carcinoma of the cervix. Am J Obstet Gynaeco. 68(4):1016-1047

21. Munoz N, Hernandez-Suarez G, Méndez F, Molano M, Posso H, Moreno V, Murillo R, Ronderos M, Meijer C, and Munoz A. Persistence of HPV 
infection and risk of high-grade cervical intraepithelial neoplasia in a cohort of Colombian women. Br J Cancer. Apr 7, 2009; 100(7): 1184 1190. doi: 10.1038/sj.bjc.6604972.

22. Franceschi S, Rajkumar $\mathrm{T}$, Vaccarella $\mathrm{S}$, Gajalakshmi V Sharmilla A. Snijders PJ, Munoz N, Meijer CJ, Herrero R: Human papillomavirus and risk factors for cervical cancer in Chennai, India: a case control study. Int J Cancer 2003, 107; 127-33. DOI: $10.1002 /$ ijc. 11350

23. Sowjanya AP, Jain M, Poly UR, Padma S, Das M, Shah KV, et al. Prevalence and distribution of high risk Human papilloma virus types in invasive sqaumous cell carcinoma of the cervix and in normal women in Andhra Pradesh, India. BMC Infect Dis 2005; 5: 116. Available from:http://www. biomedcentral.com/1471-2334/5/116
24. Bhatla N, Dar L, Patro AR, Kriplani A, Gulati A, Verma $K$, et al. Human papilloma virus type distribution in cervical cancer in Delhi, India Int $\mathrm{J}$ Gynecol Pathol 2006;25:398-402

25. Peedicayil A, Abraham P, Sathish N, John S, Shah K, Sridharan $\mathrm{G}$, et al. Human papillomavirus genotype associated with cervical neoplasia in India. Int J Gynecol Cancer 2006; 16: 1591-5

26. Dutta S, Begum R, Mazumder Indra D, Mandal SS, Mondal R, Biswas J, Dey B, Panda CK, Basu P. Prevalence of human papillomavirus in women without cervical cancer: A population-based study in Eastern India. International Journal of Gynecological Pathology .2012; 31(2): 186-191. doi: 10.1097/PGP.0b013e3182399391.

\section{How to cite this article?}

Das CR, Deka M, Bose S, Bose PD, Das GC. Demographic profile of Cervical Cancer development: a hospital based study. Int J Med Res Rev 2014;2(4):333- 339. doi: 10.17511/ijmrr.2014.i04.15 